
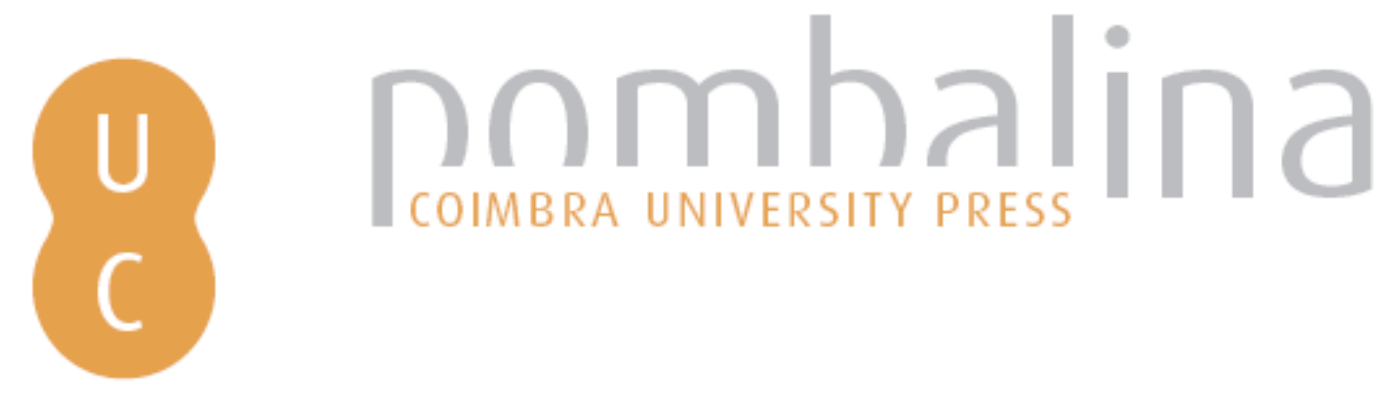

\title{
Da prática musical no mosteiro de Santa Maria de Semide
}

\author{
Autor(es): $\quad$ Monteiro, Amparo Carvas
}

Publicado por: Imprensa da Universidade de Coimbra

URL

persistente: URI:http://hdl.handle.net/10316.2/30036

DOI: $\quad$ DOI:http://dx.doi.org/10.14195/978-989-26-0567-8_6

Accessed : $\quad$ 26-Apr-2023 11:57:43

A navegação consulta e descarregamento dos títulos inseridos nas Bibliotecas Digitais UC Digitalis, UC Pombalina e UC Impactum, pressupõem a aceitação plena e sem reservas dos Termos e Condições de Uso destas Bibliotecas Digitais, disponíveis em https://digitalis.uc.pt/pt-pt/termos.

Conforme exposto nos referidos Termos e Condições de Uso, o descarregamento de títulos de acesso restrito requer uma licença válida de autorização devendo o utilizador aceder ao(s) documento(s) a partir de um endereço de IP da instituição detentora da supramencionada licença.

Ao utilizador é apenas permitido o descarregamento para uso pessoal, pelo que o emprego do(s) título(s) descarregado(s) para outro fim, designadamente comercial, carece de autorização do respetivo autor ou editor da obra.

Na medida em que todas as obras da UC Digitalis se encontram protegidas pelo Código do Direito de Autor e Direitos Conexos e demais legislação aplicável, toda a cópia, parcial ou total, deste documento, nos casos em que é legalmente admitida, deverá conter ou fazer-se acompanhar por este aviso. 


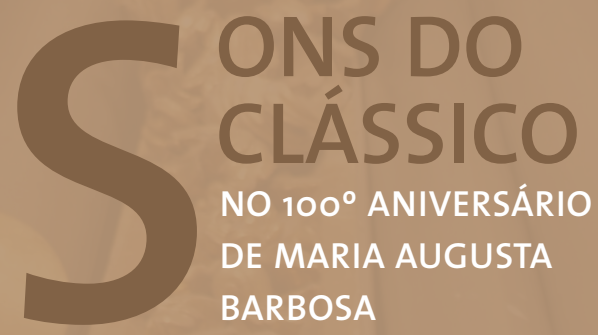

J. M. Pedrosa Cardoso

Margarida Lopes de Miranda COORDENAÇÃO 
Amparo Carvas Monteiro

Escola Superior de Educação de Coimbra

\section{DA PRÁTICA MUSICAL NO MOSTEIRO DE SANTA MARIA DE SEMIDE}

\section{Introdução}

Da longínqua e densa bruma dos tempos nos chega, uma vez mais, o toque festivo, mas sempre evocativo, do Mosteiro de Santa Maria de Semide para dar continuidade a uma liturgia multissecular, rica de ecletismo de símbolos e rituais religiosos.

Não se pretendendo este trabalho, nem exaustivo nem encerrado, seria desejável que a sua leitura suscitasse recordações de factos a que não tivemos acesso e a cuja comunicação nos mantemos abertos.

Na sociedade eminentemente rural e guerreira dos séculos XII e XIII, os grandes modelos culturais são os monges e os nobres, também orientadores da sociedade, à qual procuravam impor regras de procedimento e valores hierarquizados.

Antes do séc. XII já existiam diversos mosteiros dotados de coutos, bem como organizações episcopais e algumas colegiadas que, igualmente, dispunham de domínios próprios e ainda pequenas áreas que, em regra, pertenciam a cada igreja paroquial. Mosteiros como os do Lorvão, Arouca, Guimarães, Vacariça, Pedroso e outros já eram antigos quando foi erigido o Mosteiro de Alcobaça, entre 1148 e 1153, com base na doação de D. Afonso Henriques. No contexto destas organizações do clero regular, vivendo segundo a regra da respectiva ordem, destaca-se o Mosteiro de Santa Cruz de Coimbra (1131). 
Após a concessão do Condado Portucalense a D. Henrique ${ }^{45}$ e a D. Teresa são fundados novos mosteiros, enquanto outros são reformados ou se extinguem. Podendo ser do tipo familiar e frutuosiano distinguiam-se social e culturalmente: os segundos mais obedientes aos cânones da vida monástica, enquanto os primeiros assentavam nas fortunas das famílias dos fundadores ou protectores pertencentes à nobreza condal ou à nobreza rural da época, que neles mantinham a sua influência, como foi o caso do Mosteiro de Santa Maria de Semide, ligado à família Anaia.

A fundação do mosteiro de Semide está intrinsecamente ligada à reconquista cristã e ao progressivo alargamento do reino português no século xII, para sul, bem como à sua organização e povoamento.

Em 1131, o processo de Reconquista estava em curso e o Condado com Afonso Henriques assumia a luta pela independência contra Afonso VI (Mattoso 1993: 64). A mudança da corte de Guimarães para Coimbra, nesta data, foi "a mais transcendente de todas as decisões para a sobrevivência de Portugal como Nação Independente», sendo considerada "a cidade mais bem colocada para assumir a defesa do território face aos Árabes de que constituía fronteira» e donde se partiu "para a conquista de Lisboa e Santarém». De realçar também, a longa tradição de convivência desta urbe com os moçárabes - entre 1080 e 1116, foi importante foco de resistência contra a cultura dos clérigos vindos do Norte -, razão pela qual «ao fixar-se em Coimbra, D. Afonso Henriques, tornou-se o mais fiel protector de Santa Cruz e fez do mosteiro o centro cultural da corte» (Mattoso 1993: 68-69), contribuindo para que este se venha a tornar no centro cultural pujante e influenciador do resto do país.

A cidade mondeguina representa, então, o afastamento de Afonso Henriques da nobreza senhorial do Norte, que, ao aproximar o Norte do Sul e ao integrar a corrente pró-moçárabe, colocou em igualdade o condado portucalense e o de Coimbra, permitindo formar uma nação com regiões que se complementam.

Situada a cerca de duas léguas a sudeste de Coimbra e a um pouco menos de Miranda (do Corvo), numa área de grande potencial agrícola e na proximidade

\footnotetext{
45 A Crónica Sahagún refere que o rei D. Afonso VI «deu, com sua filha em casamento, Coimbra e a província de Portugal, que são fronteiras com os mouros» (Mattoso 1993: II-32).
} 
de um conjunto de locais fortificados da linha fronteiriça então estabelecida, Semide possuía condições favoráveis à fixação demográfica indispensável à prossecução da reconquista levada a cabo por D. Afonso Henriques.

O quadro cronológico da fundação e primeiros tempos do Mosteiro de Semide, elaborado a partir de informações sincrónicas recolhidas em fontes narrativas e diplomáticas dignas de crédito, insere estas datas: 1154, com a primeira comunidade monástica, masculina, a viver em Semide; e 1183, com a instalação das primeiras monjas beneditinas.

Com efeito, a carta de couto mandada passar por D. Afonso Henriques no dia 30 de Abril de 1154 demonstra a existência, naquele ano, de uma comunidade monástica beneditina masculina em Semide, admitindo-se que ela já pudesse estar instalada em data anterior. Este documento confere a qualidade de protectores do mosteiro a D. João Anaia, bispo de Coimbra (1147-1155) e a seu irmão D. Martim Anaia (e sua mulher Elvira Afonso), cavaleiro de Coimbra das hostes de D. Afonso Henriques, filhos de Anaia Vestrariz, asturiano e acompanhante do conde D. Henrique, a quem D. Teresa havia concedido a tenência dos castelos de Góis e Bordeiro.

A proximidade fronteiriça e a lógica militar levavam a que o monarca fizesse concessões, procurando compensar os homens que o apoiavam na guerra. A referida carta de couto de 1154 representa recompensa à família Anaia:

«[...] Ego Alfonsus ex divina providentia Portugalensium rex [...] cum regina Mahalda uxore mea vobis domno Iohanni abbati Sancte Marie de Semedi vestroque conventui et vestris successoribus in perpetuum facio cautum ad illam villam in qua monasterium edificatis, que est in territorio castri de Arouz et dicitur Semedi, de qua domnus Iohannes Colimbriensis episcopus et eius frater Martinus Annaye cum uxore sua Elvira Alfonsi et omnibus suis heredibus, me concedente [...]».

(P-Lan, Chancelaria de D. Afonso III. L I I Doações de Afonso III, fl. 21 v)

Por documento subscrito no ano de 1183, os filhos de Martim Anaia (com outros familiares) oferecem os direitos que têm sobre a Igreja de S. Pedro cum omnibus suis pertinentijs Deo et sancto Benedicto, para que sua irmã Sancha Martins e outras mulheres da mesma família pudessem estabelecer 
uma comunidade beneditina feminina em Semide. Com este documento possibilitam a formação desta nova comunidade com descendentes de Anaia Vestrariz, sendo a primeira Abadessa (1183), sua neta Sancha Martins, filha de Martim Anaia e de Elvira Afonso.

A saída dos monges e a instalação do mosteiro feminino permitiu continuar a receber, noviciar e professar outras familiares dos instituidores, mormente as descendentes das irmãs de D. Sancha que não viessem a casar. É de admitir que, para além das descendentes dos Anaia, mulheres de outras famílias da nobreza regional oriunda de outros cavaleiros de Coimbra tenham, então, ingressado no Mosteiro de Semide.

A partir da segunda metade do séc. XII, o desenvolvimento do monaquismo feminino traduz-se no aparecimento de novos mosteiros a par da transformação de cenóbios masculinos em residências de monjas.

A nobreza medieval tinha um interesse particular no controlo das instituições monásticas, sendo prática generalizada colocar nos mosteiros mulheres da nobreza de segundo grau, sobretudo em famílias com elevado número de filhas afastadas do casamento por razões de natureza sucessória e de linhagem.

A eleição para o cargo de Abadessa resultava, por regra, da estreita ligação desta à família instituidora do mosteiro, como é evidente no caso de Semide.

Os mosteiros foram centros difusores de religiosidade e de cultura e, simultaneamente, de grande relevância no plano material, no desenvolvimento, consolidação e defesa do património, o que contribuiu para o aumento gradual da sua importância e dos seus abades e abadessas.

Entre as monjas de Semide, existem referências a diversos cargos, entre os quais os de abadessa, prioresa, subprioresa, cantora-mór, segunda cantora, supridoras, mestra das noviças, sacristã, celeireira, escutas das grades, boticária e escrivã.

A abadessa era eleita pelas monjas, sendo a representante máxima da instituição, dentro e fora desta. Por exemplo, quando no séc. xiv a capacidade de desfrute sobre a área coutada foi ameaçada pelos poderes vizinhos, a abadessa de Semide invocou a carta de couto de 1154 , considerando que as monjas eram as naturais continuadoras da comunidade a quem a carta fora dirigida, justificando, assim, as prerrogativas e direitos possuídos. Por ocasião de uma demanda em que foram postas em causa as delimitações das propriedades 
monásticas, a abadessa sustentou que ao "dicto moesteiro de Semide foram dadas e outorgadas buuas grandes somas de terras e herdades as quaes deziam que lhis forom dadas e outorgadas per el rei Dom Afonso Anriquez [...] per divissooes e confrontaçães certas", vindo a ganhar a contenda (P-Cua, Pergaminhos avulsos, não numerados, de 20 de Agosto de 1363).

A prioresa era a segunda figura da instituição, cabendo-lhe algumas funções atribuídas pela abadessa. O carácter hierárquico da comunidade originava disputas pelos principais cargos, por serem aqueles cujo controle pela família patronal poderia garantir maior poder, influência e património.

Em 13 de Fevereiro de 1610, D. Afonso de Castelo Branco, bispo de Coimbra e conde de Arganil, fez deslocar as monjas beneditinas de Semide para o convento de Santa Ana que havia mandado construir na parte alta da cidade, para as religiosas de Santo Agostinho que já o habitavam. Esta mudança ocorreu em cumprimento de um breve emitido a seu pedido pelo Papa Paulo V que mandava extinguir o mosteiro de Semide, unindo-o ao de Santa Ana e passando para este todas as rendas, dízimos, direitos e propriedades daquele, devendo as monjas beneditinas semidenses conformar-se "no habito, e reza e divino officio, $e$ outros ritos e costumes regulares com a ordem de Santo Agostinho" (Benedictina Lusitana, cit. Assunção 1900: 34; P-Lan, Semide. Santa Maria, livro 1, maço 7).

Foi, porém, de curta duração esta medida, pois as recém-chegadas logo contestaram a mudança de hábito e de regra que lhes era imposta e manifestaram ao bispo-conde a sua vontade de voltar para Semide, isto é, para o seu Paraíso, como elas o denominavam. A notícia do protesto, que não foi inteiramente pacífico, alastrou pela cidade de Coimbra, tendo D. Afonso Castelo Branco, por provisão que mandou passar no dia 14 de Abril de 1610, permitido que regressassem a Semide as religiosas que assim pretendessem e permanecessem no convento de Santa Ana as que nele quisessem passar a viver, com nova regra e hábito. Como fundamento do protesto, as monjas invocaram desconhecer o teor do documento pontifício, por o mesmo não lhes ter sido previamente lido, nem dado a ler, para dele tratarem em capítulo. Após ter-lhes sido dado conhecimento do teor do documento, a maioria respondeu não consentir na mudança do hábito de S. Bento em que professaram, nem nas restantes imposições contidas no breve, regressando a Semide mais de dois terços das monjas que dele tinham vindo para Santa Ana. 
Diversos e importantes foram os privilégios concedidos ao Mosteiro de Semide. No que respeita à protecção real, pode referir-se um alvará de D. Pedro II que transcreve uma carta de D. Afonso V, colocando a abadessa, o convento e todos os seus bens sob protecção régia, a qual foi confirmada por D. João V. O mosteiro estava também isento de prestação de serviços nas obras na cidade de Coimbra, estando dispensado de nelas mandar comparecer os moradores do seu couto, privilégio que lhe foi concedido e confirmado por diversos monarcas. ${ }^{46}$ Estava ainda isento de prestação de aposentadoria e possuía jurisdição própria, com juiz eleito entre os moradores do couto (cuja eleição era ratificada pela abadessa), que julgava os litígios, podendo as partes em caso de discordância recorrer para a abadessa e desta para o rei.

As grandes mudanças políticas, os conflitos militares e epidemias tiveram consequências nefastas para o monaquismo. Por exemplo, a guerra da restauração, as invasões francesas, as lutas liberais, o corte das relações com a Santa Sé e sobretudo a extinção das ordens religiosas masculinas em 1834 e a situação de precaridade material das congregações femininas, que trouxeram às monjas de Semide "[...] duras privações [...] no aperto de uma clausura onde abundam mais as lagrimas de angustia do que o pão de cada dia" (Assunção 1900: 112). ${ }^{47}$ São provações desta natureza as que referem em carta de 31 de Março de 1843, dirigida à Câmara de Deputados do Reino, na tentativa de defesa dos seus direitos de propriedade sobre um conjunto de terrenos que possuíam nos campos de Coimbra, em ambas as margens do rio Mondego. Entre 1843 e 1845, as monjas tiveram de vender diversos objectos de prata para poderem comprar milho e outros mantimentos e estabelecer acordos com os credores para mitigar a penúria em que viviam.

\footnotetext{
46 Cf. De entre outros, P-Lan, Chanc. de D. João III, L ${ }^{\circ}$ 14, fl. 23; P-Lan, Confirmações Gerais, liv. 14, fl. 319 (em treslado de 4 de Dezembro de 1634, relativa à confirmação dos privilégios e jurisdições do couto de Semide, por D. Afonso IV, em 15 de Novembro de 1335); P-Lan, Semide, M. 182, n. 30; P-Lan, Semide, M. 182, n. 33; Chancelarias de D. Pedro I (1357-1367), p. 154-155 (n. 394); P-Lan, Doaç., L ${ }^{\circ} 62$ da Chanc. de D. Pedro II, fl. 262, carta (13 de Dezembro de 1701), de confirmação do direito de disporem de jurisdição própria); P-Lan, Chancelaria de D. João V, livro II, Padr. e Doações, fl. 76, carta (7 de Março de 1707), da confirmação de isenção do serviço de aposentadoria); P-Lan, Chanc. de D. João V, livro II, Pradr. E Doaç., fl. 72.

47 A reintrodução discreta das ordens regulares começou nos anos 60, sendo o seu crescimento tão significativo que, "nas vésperas da República, existiam em Portugal 31 congregações ou associações religiosas distribuídas por 164 casas» (Neto 2007:172).
} 
Por sua vez, Semide cuja existência remonta a tempos muito anteriores à fundação da nacionalidade portuguesa e que havia recebido foral ${ }^{48}$ de $\mathrm{D}$. Manuel no dia 13 de Janeiro de 1514, viu extinguir em 31 de Dezembro de 1853, o concelho de que foi sede até essa data.

Apesar das dificuldades, era forte a vontade das monjas de persistir no hábito, na regra e na casa em que haviam professado, pois em 5 de Janeiro de 1870, o governador do bispado de Coimbra consultou as religiosas que ainda se encontravam em Semide, sobre a sua vontade de se transferirem para outro mosteiro, ao que estas responderam negativamente.

Em Maio de 1882, ainda permaneciam no mosteiro três monjas (para além de mulheres residentes que continuaram ao seu serviço). A última monja do mosteiro beneditino de Santa Maria de Semide faleceu nele, no dia 21 de Agosto de 1896.

\section{Da igreja e do seu órgão histórico}

Da edificação medieval do cenóbio nada existe, presentemente. Devido a um incêndio que ocorreu em 1664, foi destruída a maior parte do mosteiro, sendo o actual o resultado de construções posteriores, sobretudo, dos séculos XVII e XviII. Num passado mais recente, em 16 de Agosto de 1990, o Mosteiro de Semide volta a ser vítima do fogo que consumiu o Claustro Velho, a Casa do Capítulo e a Sacristia.

A igreja foi edificada numa tipologia de ampla nave e capela-mor num dos topos e no outro está localizado o coro monástico. Da decoração sobressai a da capela-mor com diversas cenas da vida de S. Bento, sendo o retábulo em talha dourada, com duas esculturas, uma do patrono e outra de Santa Escolástica, atribuídas ao monge escultor beneditino Fr. Cipriano da Cruz. As paredes da igreja e do coro são revestidos a azulejos com motivos hagiográficos, de meados de Setecentos, de fabrico coimbrão.

\footnotetext{
48 Em virtude das muitas demandas e interpretações diversas que os letrados davam aos Velhos Forais, D. Manuel «mandou rever os cinco livros das Ordenações, nos quais mandou diminuir e acrescentar aquilo que lhe pareceu necessário para o bom governo do Reino", tarefa que levou 20 anos (Crónica do Felicíssimo Rei Dom Manuel, Cap. XXV).
} 
O templo está dividido em duas partes, ficando o coro separado por um arco com grades de ferro. No coro, na parede do fundo, está localizado o órgão histórico assente numa tribuna de madeira. A caixa do órgão em talha dourada é encimada pela figura do Rei David. Segundo o organeiro António Simões, que procedeu ao restauro do instrumento na década de 80 do séc. xx, a autoria do órgão tem vindo a ser atribuída a António Xavier Machado e Cerveira (1756-1828), provavelmente em 1788.

Porém, esta autoria e respectiva data não são conclusivas, tendo em conta, entre outros documentos, a existência de róis de despesas despendidas com alimentação do organeiro beneditino Fr. Manuel de S. Bento (autor do órgão setecentista da Real Capela de S. Miguel da Universidade de Coimbra), que referem várias deslocações deste a Semide e a Sandelgas. Com efeito, por motivo da construção do órgão da Capela da Universidade, frei Manuel de S. Bento esteve em Coimbra entre 1732 e 1734 e, posteriormente, em 1738 e 1745. Um daqueles manuscritos, datado de 11 de Novembro de 1734, está assinado pelo procurador do Colégio de S. Bento de Coimbra, Fr. António de São Gregório e por este entregue ao bacharel Mateus Monteiro, Agente da Universidade de Coimbra (P-Cua, Universidade de Coimbra. Contas (documentos diversos provenientes de várias repartições da Universidade). 1728-1737. (caixa de inumerados); Universidade de Coimbra. Contas. 1745 (caixa de inumerados); Monteiro 2002: 272-273; Monteiro 2004: 9-11). Não se pretende, contudo, atribuir-lhe a autoria do órgão do Mosteiro de Semide - aspecto digno de aprofundada investigação -, mas é de admitir a sua intervenção no mesmo.

Com a revitalização do ofício da organaria em solo português, a partir da década de 80 do séc. xx, alguns artesãos nacionais e estrangeiros começaram a dedicar-se ao património organístico do país, e graças a uma crescente consciencialização de alguns políticos e agentes culturais, encara-se, hoje em dia, com novo olhar a tarefa de conservação e de restauro dos órgãos de tubos históricos e modernos. Com efeito, entre 2002 e 2007, o instrumento histórico de Semide sofreu nova intervenção com grande critério e exigência, levada a cabo pelo organeiro Dinarte Machado.

O órgão do Mosteiro de Santa Maria de Semide é rico na composição de registos, tanto nos cheios como na base de sustentação daqueles, evidenciando um projecto de construção no sentido da variedade sonora de cheios, 
dos mais diversos timbres até à unidade artística da pirâmide harmónica, reforçado com os jogos palhetados, de acordo com informações amavelmente prestadas por Dinarte Machado.

\section{Observações organológicas}

Teclado de um só manual, cuja extensão é a seguinte: Lado esquerdo - C1 (dó1) | c 25 (dó 25); lado direito - c\#26 (dó\# 26) | f 54 (fá 54). Dois pedais que accionam os tambores acústicos, cada um com batimentos inferiores a um intervalo de meio tom: tambor de Dó e tambor de Fá; e outros dois: para anular registos cheios, assinalados com +; e anular registos de palheta em chamada, referenciados com *. Um puxador da campainha para indicações ao foleiro.

Composição do instrumento

\begin{tabular}{lll} 
MÃO ESQUERDA & & MÃO DIREITA \\
\cline { 3 - 3 } Trompa Batalha* & Clarim* \\
Trompa Real & & Oboé* \\
Cobre Símbala + & Trompa Real \\
Símbala + & Corneta Real \\
Clarão + & Símbala + \\
Vintedozena + & Nazardo + \\
Dezanovena + & Vintedozena + \\
Quinzena + & Dozena e $15^{\text {a }}+$ \\
Dozena + & Oitava Real + \\
Flautado de 6 tapado & Voz Humana \\
Flautado de 6 aberto & Flauta Romana \\
Flautado Violão & Flauta Travessa \\
Flautado de 12 aberto & Flautado de 12 aberto \\
& Flautado de 24 aberto
\end{tabular}

A registação é fundamental para a execução organística na liturgia. Ela dá a côr, o ambiente, prepara os momentos de maior densidade significativa de um cântico, torna-o mais vivo, ajuda a definir a sua função ritual, faz distinguir os vários momentos rituais pela na sua diversidade e importância, e contribui 
para a expressão de conteúdos da ação litúrgica. O organista pode em muito ser responsável por que determinada celebração aconteça de modo vivo e dinâmico, pela clara diferenciação das partes e por uma expressão musical bem integrada nas ações, permitindo, a todos, também através da música instrumental (a solo ou não) melhor e mais ativa participação (Antunes 1996: 186 ss). Em síntese, quem domina bem os materiais através de uma técnica aperfeiçoada, pode, com o seu talento, produzir uma obra de arte, com inegável nível artístico e qualidade estética. Só assim é verdadeira arte ao serviço da liturgia, exprimindo com a linguagem que lhe é própria (linguagem dos sons) e com a sua beleza expressiva, os valores da fé (Ibidem: 207).

O mosteiro semidense possuía também um clavicórdio (ou manicórdio, como também é denominado em algumas fontes) construído em meados do século xviII, referenciado no Catálogo da Exposição da Fábrica de Sons, Instrumentos de Música Europeus dos Séculos XVI a XX, editado em 1994, e por autores como Gerhard Doderer (1996) e Elisa Lessa (1998). A prática deste instrumento na corte portuguesa já se verificava no séc. xv, conforme carta de 22 de Setembro de 1428, do Infante D. Henrique, escrita em Coimbra para D. João I, seu pai, dando-lhe notícias suas e dos irmãos, especialmente a relatar-lhe como decorrera o casamento do infante D. Duarte com a infanta D. Leonor, então ali celebrado:

«O jffante meu senhor em ver damçar e camtar e em qualquer outra cousa que pode filhar prazer filhao de bom tallamte e he bem ledo e bem saao, a Deus graças. E louua mujto ho camtar da senhora a jffante e ho seu tamger do manicórdio e do damçar segumdo sua maneira, e asi dizem que baijlha».

(Monumenta Henricina 1961: III-256)

O clavicórdio era um instrumento especialmente adequado às funções exigidas e ao estudo individual da vida conventual das grandes congregações como sejam de Beneditinos, ou Agostinhos Regrantes, sendo a arte da sua construção uma tradição nacional. Em Coimbra, a oficina de instrumentos do mosteiro crúzio e a vida comunitária do mesmo, estava organizada no sentido de uma auto-suficiência, quer do ponto de vista material, quer sob o ponto de vista cultural. As fontes são abundantes e demonstradoras dessa prática 
longínqua, como refere Gerhard Doderer (1999: 35; 2005: 10), ao noticiar a visita de D. João III, no ano de 1550, à oficina da comunidade crúzia. Nos anos Quinhentos e Seiscentos, a construção e execução de manicórdios ou clavicórdios teve diversos frades dedicados, de que se destacaram D. Luís, D. Baptista de São João, D. Jerónimo dos Anjos, entre outros (Pinho 1981: 156).

\section{Da música no quotidiano das monjas}

A entrada nos conventos beneditinos estava regulada e exigia um conjunto de requisitos. Por exemplo, o ingresso era acompanhado de um dote, embora estivesse previsto que a candidata pudesse entrar sem aquele, desde que possuísse conhecimentos musicais (ingresso pela prenda de solfa e organistas), como se infere do relatório de Visita efectuada ao Mosteiro de S. Bento de Bragança, pelo Visitador Fr. Pedro de Melo, em 1698. As normas eram válidas e extensivas a todos os conventos femininos beneditinos. Dispunha o relatório:

«[...] ordeno que as muzicas examinem as freiras que tiverem melhores vozes e as ensinem, e que lhe dem lição todos os dias, a qual basta, que seja de duas horas; e que as freiras com mais temor e cuidado aprendao, e se exercitem em a solfa, mando se lhe dê de propina, mais que as outras um tostão, para que não percao o tempo em que podiao granjar pello seu trabalho alguma cousa para sua passagem [...].

[...] Também me parece conveniente que as muzicas que na religião estaõ, e entram sem dote e as tomou o convento para o ministério de ensinar e cantar, as Preladas, as não ocupem em nenhum officio da religião, excepto aquelles que pertencem ao choro, cujo exercicio he necessario para com mais decencia se celebrar o culto divino [...]».

(P-Lan, Bragança, S. Bento, cx. 1, cit. Lessa 1998: 98)

Tal como a transcrição nos indica, também Em Vozes do Convento, nos é dito que às «senhoras músicas, cantoras e tangedoras de órgão, eram concedidos privilégios próprios - dispensa da Hora de Noa, flores e alimentação 
especial - fruto do reconhecimento dos seus dotes e da importância do serviço prestado à comunidade» (Lessa 2011: 587).

A admissão da noviça era precedida de uma habilitação de genere. De entre os requisitos, a postulante deveria ter pelo menos 15 anos. Contudo, diversa documentação revela ter sido lançado o hábito a meninas com menos idade. O cerimonial para a entrada no noviciado descrito por Tomás Lino d'Assunção (1900) e Elisa Lessa (1998), evidencia a preparação, com a indispensável componente musical.

A solenidade ocorria, após proposta de admissão pela abadessa do mosteiro e votação e aceitação pelas monjas em capítulo, depois do ofício de Vésperas. A entrada era precedida de um diálogo entre a noviça e a abadessa que lhe lia a regra e seguidamente lhe lançava o hábito, entoando as monjas cantoras o hino Veni Creator Spiritus.

Ao longo de um ano de noviciado, seria submetida a três provas públicas e, vencidas estas, estaria apta para professar. Com o início do noviciado, começava também a sua vida de provações, ao longo de um ano, sob a responsabilidade da Mestra de Noviças. Esta, segundo a Regra, tinha a seu cargo a instrução, devendo "exercitar estas [as noviças] muito na oração, meditação, lição de livros espirituais, frequência de sacramentos, em jejuns, vigílias, cilícios e disciplinas [...] e cuidar que não falem com seculares, ainda que sejam parentes", não podendo "estar à conta ou em companbia de suas tias, ou parentas [mesmo as que estivessem no mosteiro]» (Assunção 1900: 67) e, apenas com a sua Mestra a quem competia a instrução - no Latim (por vezes no Português) e na Música, para entoar e acompanhar os cantos litúrgicos -, no primeiro ano do coristado.

Findo o ano do noviciado e tendo ultrapassado as provas impostas, a noviça seria admitida à profissão de fé, com parecer favorável da mestra e voto favorável das monjas.

Nesta nova cerimónia, depois de proferir o texto da profissão, a noviça entoava com a Cantora e a Mestra das Noviças a antífona Suscipe Domine, com acompanhamento de órgão. Seguidamente, dirigia-se ao altar onde depositava a sua carta de profissão. Prosseguia a cerimónia estando a noviça estendida no chão no meio do coro. O hábito era benzido e entoado o versículo que diz "Levanta-te tu que dormes. Ressurge da morte e que Cristo te ilumine». 
Após ser cantada novamente a primeira estrofe do hino Veni Creator Spiritus, a professa recebia de joelhos a cogula negra, terminando a cerimónia com o celebrante a entoar o Te Deum, enquanto na torre repicavam os sinos, anunciando o fim da cerimónia.

Após o noviciado, a formação dos monges e monjas beneditinas prosseguia durante anos, como indicam as Constituições da Ordem de S. Bento (Lisboa 1590), capítulo XXXIII. Os responsáveis da Ordem tinham a preocupação de que nos mosteiros houvesse ensino e prática musical de qualidade. As observações sobre os seus benefícios e a relevância do papel da música no quotidiano das monjas estão patentes em actas de visitações e outras fontes. A existência de horas diárias de canto e de prática instrumental estavam previstas e reguladas.

O Regulamento da Comunidade do Mosteiro de Santa Maria de Semide, datado do séc. XVII, disciplinou a vida diária no convento nos seus diversos aspectos, tais como, as regras sobre silêncio e recolhimento, as horas do Ofício e da Missa e a actividade musical vocal e instrumental. Refere, por exemplo, a existência de quatro cantoras, devendo a cantora-mor "governar e reger o coro, levantando salmos e hinos, levantar ou baixar o tom quando se cante mais de presa, ou mais devagar mas não deixar de cantar, o que for por Lei ou custume [...]" (P-Lan, Semide, Santa Maria, livro 2). No âmbito das suas funções era responsável pela direcção musical do canto litúrgico, não lhe competindo porém, decidir sobre a intervenção do órgão, aspecto que competia a quem presidia à cerimónia (Cerimonial da Congregação de S. Bento. Coimbra, 1647, livro I, título 2, cap. II).

Havia diariamente, de manhã, dois períodos destinados ao estudo do cantochão (podendo um deles ser reservado à aprendizagem de um instrumento de tecla) e outro com igual finalidade durante a tarde. Para se exercitarem na prática do órgão, deveriam tocar por turno cada uma em seu dia, e as mais adiantadas ensinar as outras monjas (P-Lan, Semide, Santa Maria, maço 8).

Também As Constituições Municipaes do Real Mosteiro de Santa Maria de Semide, aprovadas e confirmadas pelo Excelentíssimo Senhor Bispo Conde Francisco de Lemos Faria Pereira Coutinho, datadas do séc. XviII, dispunham sobre a prática musical litúrgica. Por exemplo, o cap. IX destas Constituições contém as normas para a realização do oficio divino: 
"[...] As Preladas porem mandamos, e sobre isto lhe encarregamos gravemente as suas consciências, porque vigiem muito a perfeição da celebracao do officio Divino que frequentem o Coro, cuidem, que nada con velecidade, de corrida, com pressa, ou confusamente se recite, mas de espaço e com as costumadas pauzas e [...] a respeito do canto determinão também ao Convento varias, e muitas coisas, de como, e quando devem ser cantadas, entoadas ou rezadas as suas horas canónicas, consta igualmente o cerimonial [...]. As Vésperas, Terça e Missa maior sempre devem ser cantadas, segundo a mesma constituição e acabadas se cantara quando a Prima for cantada, e ainda então sem maior solenidade, mas com outra qualquer lição sem órgão, nem mais luzes acesas [...]. Façao as Religiosas e assim se lhes mande por uzar antes do officio Divino do cantochão simples e uniforme, quanto ao do canto d'orgam ou contraponto, e mesmo que talvez se procura mais agradar aos homens, que a Deus. Por isso só com Licença do Prelado paracendo justo se poderá usar do canto d'orgam, e nunca instrumental. Do mesmo orgao se não deve uzar em Officios de Deffuntos, nem nos de Semana Sancta, nem em outras funções que a Igreja o não admite, de que as Religiosas, e principalmente organista devem ser instruídas [...]».

(P-Lan, Semide, Santa Maria, Livro 1)

Nem sempre a disciplina do convento esteve de acordo com os cânones da moral laica e menos ainda com os da moral religiosa. Houve, por vezes, situações de ruptura que motivaram a intervenção da hierarquia da Igreja e até dos monarcas, com sucessivas proibições dos Prelados Visitadores.

É bem clara a proibição contida nas Constituições Municipaes do mosteiro: [...] probibe, e manda tambem as Religiosas, que nem ainda por breves horas se vistaõ de vestidos seculares, mui menos de bomens para representações, nem comedias, nem Actos Sacramentaes, nem de vidas de santos ou santas [...] (P-Lan, Semide, Santa Maria, Livro 1).

Porém, apesar das proibições, a vida das monjas tinha momentos de fuga à rotina diária, tendo o teatro um papel importante. Em Semide, à semelhança dos restantes mosteiros da ordem, eram representados autos religiosos e profanos (especialmente realizações poético-musicais onde o vilancico ou 
chansonetas tinham um papel proeminente) com o pretexto de dar maior brilho a algumas cerimónias, como a celebração do Natal, de S. João Baptista, de S. João Evangelista, ou mesmo um novo abadessado. A representação antecedia a cerimónia litúrgica e terminava com o Te Deum ou Magnificat. Por vezes, após a representação, seguia-se a Missa, participando nela todas as intervenientes no auto que, para o efeito, tinham usado indumentárias adequadas às respectivas personagens. Estas representações começaram por ter lugar na Capela-Mor, depois no Coro e, mais tarde, nos claustros e até nas celas das abadessas, com convidados.

Tomás Assunção (1900: 187ss.) refere a representação de vários autos no Mosteiro de Semide como, por exemplo, o Auto Plausível, o Auto dos Três Pastores, o Auto do Espírito Santo e o intitulado Brinquedo jocoso representado em noite de Natal, sem indicação de data, relativamente ao qual transcreve a seguinte rubrica :

"[...] acabando de recitar-se a última quadra do motteto cantado, entra pela porta do aposento uma velha que representa uma moça (criada) da pomareira com um trajo proprio, e fica á porta vendo se, mas não entrando. Uma senhora em trage de pastor com chapéo desabado, cajado, sapatos tacheados e traz um cordeirinho debaixo do braço, encoberto com o lenço; e a velha vem esbaforida e cançada [...]».

Pela transcrição podemos também apurar que a temática dos textos não sofreu alteração profunda, pois o elemento pastoral, típico no vilancico do séc. XV e Xvi continuou a ser a grande regra nos séculos seguintes.

A festa que mais requeria vilancicos era a do Natal, o período mais alegre do ano litúrgico, tendo a configuração musical da sua celebração cambiantes distintas, cujo grau de festividade é expresso pela música através da escolha das partes que se cantam, do modo como são cantadas, da riqueza, grau de participação e articulação dos diversos intervenientes.

A tradição adoptada pela Capela privativa dos Duques de Bragança, em Vila Viçosa, de se cantarem vilancicos não só no Natal, mas também no dia da Imaculada Conceição (8 de Dezembro) e na festa dos Reis (6 de Janeiro), foi mantida senão mesmo reforçada por D. João IV, o que também nos é 
revelado nos fundos de Semide. ${ }^{49}$ Porém, a execução deste género musical sofreu alterações no reinado de D. João V, que os considerava "uma tradição primitiva", pelo que foram excluídos do culto na Capela Real e, proibidos em todas as igrejas do Reino e colónias, em 1717 e 1723, respectivamente (Horch 1969: 56; Nery 1997: 97, 101). Este monarca desejava «tornar Lisboa mais papista do que Roma" (Stevenson 1976: XI) e, de facto, a Capela Real foi remodelada à «maneira da liturgia e do ritual do Vaticano» e de acordo com as «orientações estéticas e dimensões monumentais da Capela do Papa» (Nery 1991: 87).

A influência e a prática da música profana na vida do Mosteiro de Semide foi realidade. A confrontação dos elementos profanos com os padrões sagrados tradicionais, vivida na comunidade religiosa semidense são o melhor testemunho da vitalidade dessa prática musical. Música, poesia, dança e teatro, foram ao mesmo tempo oração, arte, divertimento e espectáculo em que se combinou o som, a palavra, a cor, o gesto e o movimento.

Em Vilancicos do Século xVIII do Mosteiro de Santa Cruz de Coimbra (1983), Manuel Carlos de Brito, referindo-se a um conjunto de manuscritos musicais constituídos por Vilancicos e Romances na sua maioria anónimos, sublinha a influência do Mosteiro de Santa Cruz e a produção de algumas obras destinadas ao Porto, a Braga, Guimarães, Viseu e Semide: Tonos e Chançonetas de Natal (P-Cug Ms. 227) que possui vários Romances, Loas e Comédias; e Cansonetas de Natal e Hymno de nosso Padre Dom Gabriel de S. João Cartapacio.15. (P-Cug Ms. 240).

O MM $M^{50} 238$, proveniente dos fundos do Mosteiro de Santa Cruz, evidencia o destinatário e a data ( $\mathrm{P}^{\mathrm{a}}$ Simide|1645), título e padrão formal da composição: Chansonetas de Natal Cartapacio. 14. para dois coros, coro 1: S 1, 2, C 1, 2; coro 2: S, C 1, 2, T, B (guião), de que se apresenta excerto:

\footnotetext{
49 No entanto não nos é possível apresentar ou mesmo enumerar alguns desses documentos na medida em que o fundo de Semide está, presentemente, a ser tratado - num total de 89 livros e 36 maços -, não estando, pois, acessível ao público.

50 No canto superior esquerdo da folha de rosto está patente o ex-libris da Polyphonia (Schola Cantorum), facto comum em muitos outros manuscritos da P-Cug, por doação feita da Acção Cultural da Fábrica de Aveiro, e iniciativa de Mário Sampaio Ribeiro.
} 


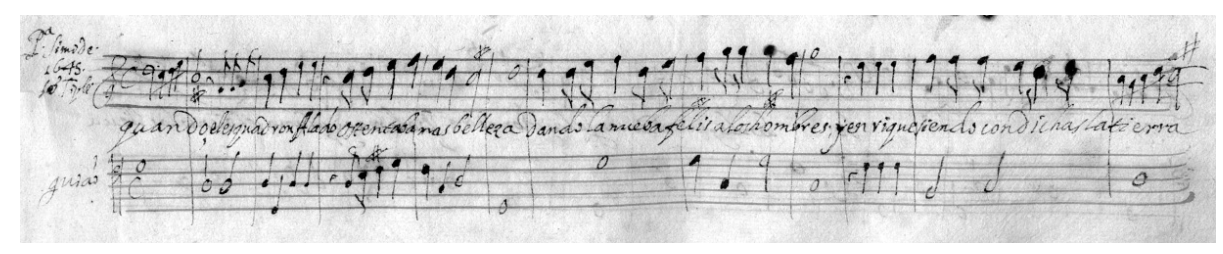

P-Cug, Quando el squadron Alado ostentaba mas belleza dando La nueba felis a los hombres, fl.6.

Ao longo da história tem sido diversa a posição da Igreja sobre determinadas práticas e uso de instrumentos na liturgia, sendo esta influenciada pelo contexto músico-cultural da época. Da mesma forma foi mais ou menos mantida a dicotomia entre instrumentos de natureza profana e sagrada, referindo-se no entanto o órgão como instrumento por excelência para a música litúrgica.

É-nos, pois, permitido concluir ter havido no mosteiro um tempo de organização e implementação litúrgica e musical, regulada e controlada, de estabelecimento de bases conducentes a uma efectiva realização musical, visível no cumprimento do cerimonial litúrgico beneditino, na participação obrigatória em todas as cerimónias litúrgicas, em especial das monjas "músicas" e cantoras, no ensino diário do canto a todas as religiosas e nas advertências sobre a representação de vilancicos, género poético-musical que nos mosteiros beneditinos surge tanto associado a cerimónias festivas integradas na liturgia como em momentos informais, particularmente apreciados em Semide.

A documentação estudada permite traçar um quadro da actividade musical que existiu na comunidade semidense no triplo papel (litúrgico, educativo e lúdico), que a música assumiu na vida comunitária. É, igualmente, evidente o contributo significativo desta comunidade e da sua intensa actividade musical quotidiana continuada de forma profícua, no desenvolvimento da arte organística e na arte de construção deste instrumento. 


\section{Referências Bibliográficas}

P-Cua, Coleção Coronel Belisário Pimenta. Miranda do Corvo. Semide. Foral Manuelino do Couto de Semide (1514).

P-Cua, Coleção Coronel Belisário Pimenta. Documentos diversos (1695-1856).

P-Cua, Semide. Pergaminhos avulsos, não numerados, de 20 de Agosto de 1363.

P-Cua, Semide. Pergaminhos avulsos: cx de pergaminhos não numerados.

P-Cua, Universidade de Coimbra. Contas (documentos diversos provenientes de várias repartições da Universidade). 1728-1737. (caixa de inumerados).

P-Cua, Universidade de Coimbra. Contas. 1745 (caixa de inumerados).

P-Cug, MM. 238, MM 227, MM 240, MM 535, MM 704.

P-Lan, Bragança, S. Bento, caixa 1.

P-Lan, Depósito, Cartório de Semide, n. 180.

P-Lan, Semide. M. 182, n. 30 e n. 33.

P-Lan, Chanc. de D. Afonso III. L I I de Doações de Afonso III.

P-Lan, Chanc. de D. Pedro I (1357-1367), p. 154-155 (n. 394).

P-Lan, Chanc. de D. João III, L $\mathrm{L}^{\mathrm{o}}$ 14, fl. 23.

P-Lan, Chanc. de D. João V, L II, Pradr. e Doações, fl. 72 e 76.

P-Lan, Confirmações Gerais, liv. 14.

P-Lan, Doaç., L 62 da Chanc. de D. Pedro II, fl. 262 e 262 v.

P-Lan, Semide. Santa Maria, livro $\mathrm{n}^{\circ} 1$.

P-Lan, Semide. Santa Maria, livro $\mathrm{n}^{\circ} 2$.

P-Lan, Semide. Santa Maria, maço 8. Livro dos Costumes.

P-Lan, Semide. Santa Maria, maço 10, Diário de 1825-1853.

P-Lan, Semide. Santa Maria, Lembranças/Diário de 1846-1850.

P-Lan, Semide. Santa Maria. Livro de Sacristia, $\mathrm{n}^{\circ} 19, \mathrm{n}^{\circ} 20, \mathrm{n}^{\circ} 21, \mathrm{n}^{\circ} 22$.

Antunes, José Paulo da Costa (1996) «Soli Deo Gloria» Um contributo interdisciplinar para a fundamentação da dimensão musical da liturgia cristã. Porto: Universidade Católica Portuguesa/Fundação Eng ${ }^{\circ}$. António de Almeida.

Assunção, Tomás Lino d' (1900), As Monjas de Semide. Coimbra: França Amado Editor.

Brito, Manuel Carlos de (1983), Vilancicos do Século xVII do Mosteiro de Santa Cruz de Coimbra. Lisboa: FCG (Portugaliae Musica, XLIII). 
Brito, Manuel Carlos de (1989), Estudos de História da Música em Portugal. Lisboa: Editorial Estampa.

Catálogo da Exposição Fábricas de Sons, Instrumentos de Música Europeus dos Séculos XVI $a$ XX. Lisboa: Electa, Museu da Música. Lisboa Capital Europeia da Cultura, 94. Lisboa.

Cerimonial da Congregação dos Monges Negros Da Ordem do Patriarcha S. Bento do Reyno de Portugal. Coimbra: Officinas de Diogo Gomez de Loureyro e de Lourenço Craesbeek, 1647.

Conde, António Linage (1973), Los orígenes del monacato beneditino en la Península Iberica. 3 vols. Leão: Centro de Estudios e Investigación 'San Isidro'.

Constituições da Ordem de S. Bento (1590). Lisboa: António Alvarez, impressor.

Dias, Geraldo J. A. Coelho (1999), "O Mosteiro das Beneditinas de Bragança e as Visitações do Bispo Diocesano”. Actas do Congresso Histórico Páginas da História da Diocese de Bragança-Miranda. Bragança: Comissão de Arte Sacra de Bragança--Miranda, p. 445-468.

Doderer, Gerhard (1996), "A arte Organística em Portugal no Passado e no Presente". Revista da APEM 80 (Lisboa) 3-7.

Doderer, Gerhard (1994), "Instrumentos de tela e corda portugueses dos séculos XVI, XVII e xvIII: clavicórdios, cravos e pianos-fortes”. Catálogo da Exposição Fábricas de Sons, Instrumentos de Música Europeus dos Séculos xVI a Xх. Lisboa: Electa, p. 21-28.

Doderer, Gerhard (1999), "Os Instrumentos de tela e corda em Portugal do Renascimento ao Romantismo", in Arte e Música. Iconografia musical na pintura do séc. $X V$ ao séc. $X X$. Lisboa: Museu da Música, p. 34-41.

Doderer, Gerhard e Van der Meer, John Henry (2005), Cordofones de Tecla Portugueses do Século XVIII: Clavicórdios, Cravos, Pianofortes e Espinetas. Lisboa: FCG.

Fr. Leão de S. Tomás (1974), Benedictina Lusitana, tomos I-II. Notas críticas de José Mattoso. Lisboa: Imprensa Nacional-Casa da Moeda.

Góis, Damião de (1566), Chronica do Felicíssimo Rei Dom Emmanuel. Lisboa.

Gomes, Saúl António (1988), "Documentos medievais de Santa Cruz de Coimbra-I. Arquivo Nacional Torre do Tombo". Estudos Medievais, ${ }^{\circ} 9$.

Horch, Rosemarie Erika (1969), Vilancicos da Colecção Barbosa Machado. Rio de Janeiro: Biblioteca Nacional.

Lessa, Elisa Maia da Silva (1998), Os Beneditinos Portugueses (Séculos XVII a XIX). Centros de Ensino e Prática Musical. 2 vols. Lisboa: Universidade Nova de Lisboa. Tese doutoral.

Lessa, Elisa, (2011) "Vozes do Convento", in Esplendor da austeridade. Mil anos de empreendedorismo das ordens e congregações em Portugal: Arte, Cultura e Solidariedade. Dir. José Eduardo Franco. Lisboa: INCM, p. 587.

Machado, Diogo Barbosa (1759), Bibliotheca Lusitana. Tomos I-IV. Lisboa: Oficina Francisco Luiz Ameno. 
Mattoso, José (1976), "A Introdução da Regra de S. Bento na Península Ibérica”, in Bracara Augusta, vol. XXX (69), p. 97-111.

Mattoso, José (1993), “A Monarquia Feudal”, in História de Portugal. Dir. José Mattoso. Lisboa: Círculo de Leitores, vol. II, p. 64, 68-69.

Melo, Maria Teresa Osório de (1992), O Mosteiro Beneditino de Santa Maria de Semide. Coimbra: Minerva.

Monteiro, Maria do Amparo Carvas (2002), Da Música na Universidade de Coimbra (1537-2002). Coimbra: FLUC. Tese de doutoramento.

Monteiro, Maria do Amparo Carvas (2004), "O órgão da Capela de S. Miguel da Universidade de Coimbra. Identificação do organeiro e de outros artífices e datação do instrumento", in Munda, 47 (Coimbra, Maio, 2004) 3-14.

Nery, Rui Vieira e Castro, Paulo Ferreira de (1999), História da Música (Sínteses da Cultura Portuguesa). Lisboa: Comissariado para a Europália 91/Portugal/IN-CM.

Nery, Rui Vieira (1997), "O Vilancico Português do Séc. xvII. Um fenómeno intercultural", in Portugal e o Mundo. O Encontro de Culturas na Música. Lisboa: Publicações Dom Quixote, p. 91-102.

Neto, Vitor (2007) "Igreja Católica e anticlericalismo, 1858-1910", in Progresso e Religião. A República no Brasil e em Portugal 1889-1910. Coord. Amadeu Carvalho Homem. Armando Malheiro da Silva. Artur César Isaía. Coimbra: Imprensa da Universidade de Coimbra.

Pimenta, Belisário (1958), "As cartas do Infante D. Pedro à Câmara de Coimbra (1429-1448)", in Boletim da Biblioteca da Universidade de Coimbra, ${ }^{\circ}$ XXIII, p. 453-532 (doc. XXI).

Pinho, Ernesto Gonçalves de (1981), Santa Cruz de Coimbra. Centro de Actividade Musical nos Séculos XVI e XVII. Lisboa: FCG.

Smith, Robert C. (1968), Frei Cipriano da Cruz. Escultor de Tibães. Porto: Livraria Civilização.

Stevenson, Robert (1976) Vilancicos Portugueses. Lisboa: FCG (Portugaliae Musica, Série A-XXIX).

Valença, Manuel (1990), A Arte Organística em Portugal (c.1326-1750). Braga: Editorial Franciscana.

Valença, Manuel (1995), A Arte Organística em Portugal - Depois de 1750. Braga: Editorial Franciscana.

Weber, Édith (1982), Le Concile de Trente et la musique. Paris: Honoré Champion. 